\title{
Состав, структура и селективная сорбция ионов цезия алюмосиликатным сорбентом, полученным из отходов калийногопроизводства ОАО «Беларуськалий»
}

\author{
Леонтьева Т.Г. ${ }^{1}$, Москальчук Л.Н. ${ }^{2}$, Баклай А.А. ${ }^{1}$, Маковская Н.А. ${ }^{1}$ \\ ${ }^{1}$ Государственное научное учреждение «Объединенный институт энергетических и ядерных \\ исследований - Соснь» Национальной академии наук Беларуси, Минск, Республика Беларусь \\ ${ }^{2}$ Белорусский государственный технологический университет, Минск, Республика Беларусь
}

Поступила в редакцию 28.05.2018 г.

DOI: https://doi.org/10.17308/sorpchrom.2018.18/599

Представлены результаты комплексного исследования алюмосиликатного сорбента, полученного в результате кислотно-водной обработки образца глинисто-солевого шлама - крупнотоннажного отхода калийного производства ОАО «Беларуськалий» Республики Беларусь. Установлен его вещественный состав и коллоидно-химические характеристики. По минералогическому составу алюмосиликатный сорбент относится к гидрослюдистой группе. Выявлена высокая эффективность извлечения данным сорбентом ионов цезия из водного раствора. Определены коэффициенты распределения цезия и значения сорбционной селективной емкости цезия для двух типов сорбционных центров алюмосиликатного сорбента.

Ключевые слова: глинисто-солевые шламы, структура, алюмосиликатный сорбент, сорбция, цезий, дисперсность, изотерма, коэффициент распределения.

\section{Composition, structure and selective sorption of cesium ions by aluminosilicate sorbent derived from potassium industry waste of JSC «Belaruskali»}

\author{
Leont'yeva T.G. ${ }^{1}$, Moskal'chuk L.N. ${ }^{2}$, Baklay A.A. ${ }^{1}$, Makovskaya N.A. ${ }^{1}$ \\ ${ }^{I}$ SSI «Joint Institute for Power and Nuclear Research - Sosny», National Academy of Sciences of Belarus, \\ Minsk, Republic of Belarus \\ ${ }^{2}$ Belarusian State Technological University, Minsk, Republic of Belarus
}

Environmental problems related to the contamination of aquatic environments by radionuclides remain valid even today due to a number of accidents at nuclear power plants. In modern technologies for cleaning aqueous media based on sorption processes, natural clays of various compositions are widely used because of their availability and low cost. Natural clays, depending on the type and content of layered clay minerals in their composition, differ very greatly in their sorption properties with respect to radionuclides. The aim of this work is to investigate the selective sorption of $\mathrm{Cs}^{+}$with an aluminosilicate sorbent (AS) obtained by acid-water treatment of clay-salt slimes (CSS) sample which are large-tonnage waste of the potassium production of JSC "Belaruskali" (Soligorsk, Belarus). The main mineral phases in the CSS are illite (50 wt. \%) and dolomite (20 wt. \%). It is known that illite with compacted layers and extended zones at their ends is characterized by high selective properties towards to cesium. The acid-water treatment of the CSS sample results in an increase in the number of highly selective sorption sites in the sorbent, and mainly due to an increase in illite content, since this clay mineral determines the selective sorption of cesium trace amounts 
in the edge wedge-shaped region of inter-pack spaces. The AS sample was studied by the following modern methods: X-ray diffraction, X-ray spectral microanalysis, dispersed analysis, and transmission electron microscopy. It is pointed out that in comparison with the initial CSS samples in the AS samples the values of the following indicators have increased: the content of illite is 1.3 times, the specific surface is 2.4 times and the values of selective sorption towards to cesium is 2.1 times.

The content of particles with a size of less than 10 microns, which is $87.3 \mathrm{wt} \%$, the sample AS refers to a highly disperse group of clay materials, and by mineral composition - to the hydromicaceous group (the content of illite is $65.2 \mathrm{wt}$. \%). The sorption of cesium ions on AS sample with a specific surface area of $66 \pm 4 \mathrm{~m}^{2} / \mathrm{g}$ at $\mathrm{Cs}^{+}$ion concentration in a solution of less than $2 \cdot 10^{-4} \mathrm{~mol} / \mathrm{dm}^{3}$ is described by the Langmuir model.

The calculated values of cesium distribution coefficients for the two types of sorption centers of the AS sample are $8.3 \cdot 10^{3}$ and $8.1 \cdot 10^{2} \mathrm{dm}^{3} / \mathrm{kg}$, and the values of selective sorption of cesium are 0.4 and $14.6 \mathrm{mmol} / \mathrm{kg}$. A promising application of aluminosilicate sorbent based on CSS is purification of natural water from ${ }^{137} \mathrm{Cs}$, rehabilitation of radioactively contaminated territories.

Keywords: clay-salt slimes, structure, aluminosilicate sorbents, sorption, cesium, dispersion, isotherm, distribution coefficient.

\section{Введение}

Накопление и распространение радионуклидов в природных экосистемах происходит вследствие техногенных катастроф, функционирования атомных электростанций и предприятий по переработке радиоактивных материалов. Для очистки водных сред от радионуклидов применяются методы, основанные на процессах соосаждения и сорбции $[1,2]$. Данные методы позволяют использовать широкий спектр сорбционных материалов, среди которых природные глинистые материалы находят все большее применение, что обусловлено их достаточно высокой емкостью, избирательностью, сравнительно низкой стоимостью и доступностью [3-8]. Использование природных глин в качестве эффективных сорбентов ${ }^{137} \mathrm{Cs}$ обусловлено присутствием в них глинистых минералов с кристаллической решеткой $2: 1$ типа слюд, которые широко распространены в природе. Слюды представляют собой слоистые силикаты, образованные слоями кремнекислородных тетраэдров и алюмогидроксильных октаэдров, имеющие в кристаллической решетке изоморфные замещения катионов $\mathrm{Si}^{4+}$ и $\mathrm{Al}^{3+}$ на катионы меньшего заряда $[9,10]$. В работах $[8,11-12]$ показано, что сорбционные свойства глинистых материалов по отношению к цезию напрямую зависят от содержания глинистых минералов и их структурных особенностей. Сорбция ${ }^{137} \mathrm{Cs}$ в почвах и грунтовых водах происходит на монтмориллоните и иллите [13-15]. Для последнего при следовых концентрациях цезия сорбция выше [8, 16-18].

До настоящего времени остается нерешенной проблема снижения миграции ${ }^{137} \mathrm{Cs}$ в экосистемах некоторых районов России, Беларуси, Украины и Японии, загрязненных в результате аварий на Чернобыльской АЭС, АЭС «Фукусима-1» и др. Для снижения миграции ${ }^{137} \mathrm{Cs}$ в экосистемах требуется большое количество дешевых и эффективных сорбционных материалов с высоким содержанием таких глинистых минералов, как иллит и монтмориллонит [19-21].

В качестве вторичного минерального ресурса для получения сорбента ${ }^{137} \mathrm{Cs}$ предлагается рассматривать глинисто-солевые шламы (ГСШ) - крупнотоннажные отходы калийного производства ОАО «Беларуськалий», образующиеся в процессе обогащения сильвинитовой руды. ГСШ представляют собой нерастворимый осадок (н.о.) глины в насыщенном растворе водорастворимых солей $\mathrm{KCl}$ и $\mathrm{NaCl}$. Установлено [22], что основными минералами в составе ГСШ являются иллит, доломит и калиевый полевой шпат. По состоянию на 01.01.2016 объем накопленных ГСШ в шламохранилищах ОАО «Беларуськалий» составляет более 111 млн. т. Исходя из изложенного, получение алюмосиликатных сорбентов с высоким содержанием ил- 
лита и обоснование возможности их применения в сорбционной технологии очистки природных вод и почвенных растворов от ${ }^{137} \mathrm{Cs}$ позволит решить проблему утилизации ГСШ, что определяет актуальность и необходимость проведения данных исследований.

\section{Теоретическая часть}

В работах [23-25] описаны теоретические аспекты селективной сорбции цезия глинистыми минералами с кристаллической решеткой $2: 1$ типа иллита. При изучении сорбции цезия иллитом выделены три основных типа сорбционных центров, различающихся по их селективности в отношении цезия. В соответствии с установившейся международной терминологией данные сорбционные центы обозначают следующим образом:

Regular Exchange Sites (RES) - неселективные сорбционные центры, расположенные на плоских внешних гранях минералов, которые характеризуются высокой емкостью и низкой селективностью по отношению к цезию;

Frayed Edge Sites (FES) - селективные сорбционные центры, расположенные на ребрах и в области клиновидных краевых областей межпакетных пространств кристаллической решетки минералов типа иллита и обладающие меньшей емкостью и высокой селективностью по отношению к цезию;

High Affinity Sites (HAS) - центры особо высокой селективности по отношению к цезию, расположенные в глубине межпакетного пространства кристаллической решетки минералов типа иллита.

Между показателями системы слоистый минерал - раствор, согласно данным работы [23], установлена связь, которая определяется выражением

$$
K_{d}\left[C_{\mathrm{M}}\right]=K_{c}\left(\mathrm{Cs}^{+} / \mathrm{M}^{+}\right)[\mathrm{FES}],
$$

где $K_{d}$ - коэффициент распределения обменной формы цезия, дм ${ }^{3} / \kappa г ; ~\left[C_{\mathrm{M}}\right]-$ концентрация катиона $\mathrm{M}^{+}$в растворе, моль/дм ${ }^{3}$; [FES] - емкость селективной сорбции, моль/кг; $K_{\mathrm{c}}\left(\mathrm{Cs}^{+} / \mathrm{M}^{+}\right)$- коэффициент селективности ионного обмена $\mathrm{Cs}^{+}$на катион $\mathrm{M}^{+}$ на местах FES.

Величина $K_{d}\left[\mathrm{C}_{\mathrm{M}}\right]$ или $K_{\mathrm{c}}\left(\mathrm{Cs}^{+} / \mathrm{M}^{+}\right)[\mathrm{FES}]$ постоянна в широком интервале концентраций $\mathrm{M}^{+}$в растворе при условии, что доля $\mathrm{M}^{+}$на FES при следовых количествах $\mathrm{Cs}^{+}$стремится к единице. Выражение (1) определяет такой показатель, как потенциал связывания радиоцезия (Radiocaesium Interception Potential - RIP(K)), характеризующий способность сорбционных материалов в условиях контролируемых селективной сорбцией, удерживать катионы цезия в присутствии конкурирующего катиона $\mathrm{K}^{+}$. В природных водных средах ${ }^{137} \mathrm{Cs}$ и стабильный цезий находятся в следовых концентрациях и практически полностью сорбируются на высокоселективных центрах FES, а конкурирующими катионами для них являются $\mathrm{K}^{+}$и $\mathrm{NH}_{4}^{+}[23,24]$.

Целью настоящей работы является изучение селективной сорбции ионов цезия образцом алюмосиликатного сорбента из водных растворов.

\section{Эксперимент}

Для получения алюмосиликатного сорбента использовался образец ГСШ, отобранный из шламохранилища 3-го рудоуправления ОАО «Беларуськалий» (г. Солигорск, Республика Беларусь). Основными минеральными фазами в составе нерастворимого в воде осадка ГСШ являются иллит, доломит и калиевый полевой шпат, а

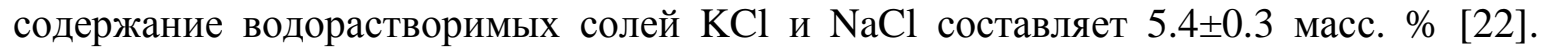
Увеличить сорбционную способность образца ГСШ по отношению к ионам цезия 
предполагается за счет его обогащения иллитом путем удаления пустой породы карбонатных минералов (доломита, кальцита), а также снижения содержания водорастворимых солей $\mathrm{KCl}$ и $\mathrm{NaCl}$ и гипса. Для этого использовали кислотно-водную обработку исходного образца ГСШ.

Образец алюмосиликатного сорбента (АС) получали из образца ГСШ, который предварительно высушивали до воздушно-сухого состояния и измельчали. Затем образец ГСШ обрабатывали $0.1 \mathrm{M}$ раствором $\mathrm{HCl}$ в статических условиях при периодическом перемешивании в течение 1 ч. Объем раствора $\mathrm{HCl}$, используемого для разрушения доломита и кальцита, рассчитывали исходя из их содержания в ГСШ. После отстаивания в течение 1 сут надосадочную жидкость сливали, а образец ГСШ тщательно промывали дистиллированной водой при соотношении фаз твердое: жидкое равным 1 : 5. Операцию промывки образца ГСШ после отстаивания повторяли до исчезновения реакции на хлорид и сульфат-ионы. Полученный образец АС высушивали до постоянной массы при температуре $105^{\circ} \mathrm{C}$.

Исследование образца АС осуществляли в соответствии с фундаментальным принципом физико-химического анализа сорбционных материалов, который опирается на взаимосвязь состав - морфология (структура) - сорбционные свойства. Минералогический состав образцов ГСШ и АС определяли методом рентгеновской дифрактометрии с помощью рентгеновского дифрактометра Ultima-IV (Rigaku, Германия) с использованием CuK-излучение и графитового монохроматора. Рабочий режим - 40 кВ и 40 мА. Для расшифровки рентгенограмм использовали программу Jade 6.5 (MDI) с с порошковой базой данных PDF-2. Количественный минеральный состав образцов ГСШ и АС определяли методом полнопрофильной обработки рентгеновских картин от неориентированных препаратов по методу Ритвельда в программном продукте программе BGMN. Химический состав образцов ГСШ и АС анализировали по данным энергодисперсионной рентгеновской спектрометрии, реализуемой на приставке JED-2201 для электронного микроскопа JSM-5610LV (JEOL, Япония). Гранулометрический состав образцов ГСШ и АС определяли методом дифракции лазерного излучения на лазерном анализаторе частиц Analysette 22 MicroTec (Fritsch, Германия) с диапазоном измерения 0.1-602.5 мкм. Удельную поверхность алюмосиликатного сорбента определяли методом низкотемпературной адсорбции азота с использованием прибора NOVA 2200 (Quantachrome Corp., CША). Морфологические исследования образца АC проводили с помощью сканирующего электронного микроскопа JSM-5610LV и просвечивающего электронного микроскопа TITAN 80-300 TEM/STEM (FEI Company, CШA) с ускоряющим напряжением $300 \mathrm{\kappa B}$.

Для изучения селективной сорбции катионов $\mathrm{Cs}^{+}$на образцах ГСШ и $\mathrm{AC}$ в статических условиях использовали метод, изложенный в работах $[23,26]$. Метод количественного определения емкости FES на глинистых материалах основан на изучении изотермы сорбции $\mathrm{Cs}^{+}$при блокировании поверхностных неселективных центров RES катионами $\mathrm{Ca}^{2+}$, обладающих большим ионным радиусом. По стерическим причинам гидратированые катионы $\mathrm{Ca}^{2+}$ не имеют доступ к центрам селективной сорбции FES, на которых и происходит ионный обмен $\mathrm{Cs}^{+}$с катионами $\mathrm{K}^{+}$и $\mathrm{NH}_{4}{ }^{+}$. В данном эксперименте насыщение неселективных сорбционных центров RES образца сорбента катионами $\mathrm{Ca}^{2+}$ не проводилось в связи с тем, что емкость RES ими уже насыщена. Навеску сорбента массой 0.1 г помещали в поликарбонатную центрифужную пробирку и уравновешивали с $10 \mathrm{~cm}^{3}$ модельного раствора, содержащего стабильный $\mathrm{Cs}^{+}$и радиоактивный ${ }^{137} \mathrm{Cs}$ без носителя с удельной активностью $2 \cdot 10^{5}$ Бк/дм ${ }^{3}$. Модельный раствор готовили растворением нитрата цезия марки х.ч. в водопроводной воде, при этом концентрация неактивного $\mathrm{Cs}^{+}$изменялась в интерва- 
ле от $2.2 \cdot 10^{-8}$ до $10^{-2}$ моль/дм³ . Образцы ГСШ и сорбента выдерживали в модельном растворе в течение 24 ч, что обеспечивает установление сорбционного равновесия $[23,26]$. По окончании данного времени взаимодействия в системе сорбент - раствор суспензия центрифугировалась (15 мин, 6000 об/мин), удельная активность ${ }^{137} \mathrm{Cs}$ измерялась в жидкой фазе до и после уравновешивания с твердой фазой гаммаспекрометрическим методом на приборе РУС-91М. Содержание неактивного $\mathrm{Cs}^{+}$, сорбированного в твердой фазе сорбента $\left(C_{\mathrm{T}}\right)$ и в растворе $\left(C_{\mathrm{p}}\right)$ рассчитывали по формулам:

$$
\begin{aligned}
& C_{\mathrm{T}}=\left(C_{0}-C_{\mathrm{p}}\right) \frac{V}{m}, \\
& C_{\mathrm{p}}=\frac{C_{0}}{1+K_{d} \frac{V}{m}},
\end{aligned}
$$

где $C_{0}$ и $C_{\mathrm{p}}$ - исходная и равновесная концентрация катионов $\mathrm{Cs}^{+}$в растворе, моль/дм ${ }^{3} ; V$ - объем раствора, дм ${ }^{3} ; m$ - масса образца АС, кг.

Коэффициент межфазного распределения ${ }^{137} \mathrm{Cs}\left(K_{d}\right.$, дм $\left.{ }^{3} / \kappa г\right)$ определяли следующим образом:

$$
K_{d}=\frac{A_{0}-A_{p}}{A_{p}} \cdot \frac{V}{m}
$$

где $A_{0}$ и $A_{\mathrm{p}}$ - исходная и равновесная удельная активность ${ }^{137} \mathrm{Cs}$ в растворе, Бк/дм ${ }^{3}$.

\section{Обсуждение результатов}

В табл. 1 приведен минералогический состав исходного образца ГСШ и полученного образца алюмосиликатного сорбента, согласно которому содержание иллита в образце АС увеличилось в 1.3 раза по сравнению с исходным образцом ГСШ.

Таблица 1. Минералогический состав ГСШ и алюмосиликатного сорбента

\begin{tabular}{|c|c|c|c|c|c|c|c|}
\hline \multirow{2}{*}{ Образец } & \multicolumn{7}{|c|}{ Содержание, масс. \% } \\
\cline { 2 - 8 } & Иллит & Доломит & Микроклин & Кварц & Гипс & Хлорит & Кальцит \\
\hline ГСШ & 50.2 & 20.0 & 18.8 & 4.9 & 3.1 & 1.7 & 1.3 \\
\hline $\mathrm{AC}$ & 65.2 & - & 27.8 & 7.0 & - & - & - \\
\hline
\end{tabular}

Методом рентгеноспектрального микроанализа установлен химический состав образцов ГСШ и АС, который представлен в табл. 2.

Таблица 2. Химический состав образцов ГСШ и АС

\begin{tabular}{|c|c|c|c|c|c|c|c|c|c|c|c|}
\hline \multirow{2}{*}{ Образец } & \multicolumn{10}{|c|}{ Содержание, масс. \% } \\
\cline { 2 - 13 } & $\mathrm{SiO}_{2}$ & $\mathrm{Al}_{2} \mathrm{O}_{3}$ & $\mathrm{~K}_{2} \mathrm{O}$ & $\mathrm{CaO}$ & $\mathrm{MgO}$ & $\mathrm{FeO}$ & $\mathrm{Na}_{2} \mathrm{O}$ & $\mathrm{TiO}_{2}$ & $\mathrm{SO}_{3}$ & $\mathrm{Cl}$ & $\mathrm{ZnO}$ \\
\hline$Г С Ш$ & 39.29 & 11.58 & 6.86 & 12.91 & 8.11 & 7.49 & 3.03 & 0.49 & 3.32 & 4.80 & 2.14 \\
\hline $\mathrm{AC}$ & 60.60 & 16.01 & 8.09 & 0.46 & 3.72 & 8.91 & - & 2.20 & - & - & - \\
\hline
\end{tabular}

Анализ данных табл. 2 показывает, что в процессе обогащения увеличивается доля оксидов кремния и алюминия в 1.5 и 1.4 раза соответственно. Это связано с тем, что в процессе обогащения повышается содержание глинистой составляющей (иллита). Как следует из данных рентгенофазового и рентгеноспектрального анализов (табл. 1 и 2), увеличение содержания иллита в образце АС произошло в результате разрушения карбонатов (доломита, кальцита) и вымывания водорастворимых солей $\mathrm{KCl}$ и $\mathrm{NaCl}$ и гипса, входящих в состав исходного образца ГСШ. 
Результаты дисперсного анализа распределения частиц по размерам, а также их содержания в образцах ГСШ и АС представлены в табл. 3.

Таблица 3. Гранулометрический состав образцов ГСШ и АС

\begin{tabular}{|c|c|c|c|c|c|c|c|c|}
\hline \multirow{2}{*}{ Образец } & \multicolumn{7}{|c|}{ Содержание фракций с размером мкм, масс. \% } & \\
\cline { 2 - 9 } & $0.05-1$ & $1-2$ & $2-3$ & $3-4$ & $4-5$ & $5-10$ & $10-20$ & $20-50$ \\
\hline ГСШ & 5.62 & 10.08 & 8.16 & 7.16 & 7.20 & 28.77 & 32.86 & 0.15 \\
\hline АС & 8.97 & 16.71 & 13.94 & 9.86 & 7.92 & 29.78 & 12.73 & - \\
\hline
\end{tabular}

Из данных табл. 3 следует, что в результате кислотно-водной обработки исходного образца ГСШ число частиц с размером менее 10 мкм увеличилось в 1.3 раза для образца АС, при этом его удельная поверхность $\left(66 \pm 4 \mathrm{~m}^{2} / \Gamma\right)$ возросла в 2.4 раза по сравнению с исходным образом ГСШ $\left(28 \pm 2 \mathrm{~m}^{2} / \Gamma\right)$.

В соответствии с классификацией глинистого сырья [27] по содержанию тонкодисперсных фракций к высокодисперсным относятся глинистые материалы, в которых содержание частиц с размером менее 10 мкм составляет свыше 85 масс. \%. Анализ данных табл. 3 показывает, что образец алюмосиликатного сорбента относится к высокодисперсной группе глинистых материалов, так как содержание частиц с размером менее 10 мкм составляет 87.3 масс. \%. Кроме того, в зависимости от минерального состава образец АС относится к гидрослюдистой группе, поскольку содержание иллита (гидрослюды) превышает 50 масс. \% (табл. 1) [27]. Полученные результаты исследований гранулометрического состава сорбента хорошо согласуются с данными определения минералогического состава, согласно которым содержание иллита в образце АС увеличилось в 1.3 раза по сравнению с исходным образцом ГСШ.

На рис. 1 приведены изображения микростроения частиц образца АС.

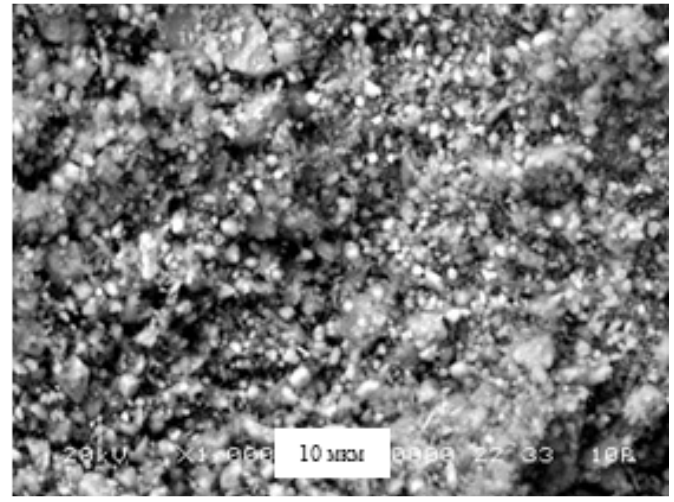

a

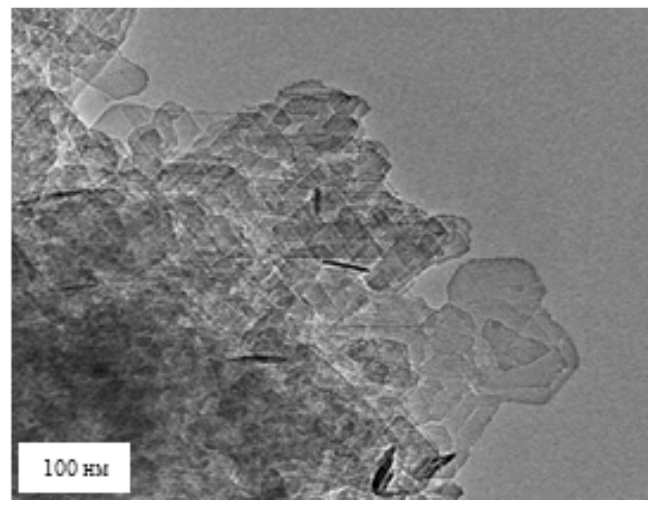

б

Рис. 1. Изображения микрочастиц образца АС, полученные методом сканирующей (а) и просвечивающей (б) электронной микроскопии

Характерная особенность рассматриваемой микроструктуры образца алюмосиликатного сорбента - наличие не только ультрамикроагрегатов размером 1-2 мкм, но и меньших размеров. В свою очередь эти агрегаты имеют довольно сложное строение. Они состоят из агломератов пластинчатых наночастиц, размеры которых находятся в диапазоне от 10 до 100 нм (рис. 1б). На изображении (рис. 1б), полученном с помощью просвечивающей электронной микроскопии (ПЭМ) преобладают наночастицы, имеющие гексагональную форму близкую к изометричной, с четкими контурами и многочисленными ступенями скола на базальной поверхности. Из-за сильной изменчивости толщины наночастиц их плотность на ПЭМ-изображении 
крайне неоднородна: от темных до светлых и совершенно прозрачных [10]. Такое строение частиц в образце алюмосиликатного сорбента способствует формированию активной поверхности для протекания сорбционного процесса.

Емкость селективной сорбции для образцов ГСШ и АС определяли по изотермам сорбции цезия в координатах $\lg C_{\mathrm{T}}-\lg C_{\mathrm{p}}$, которые представлены на рис. 2.

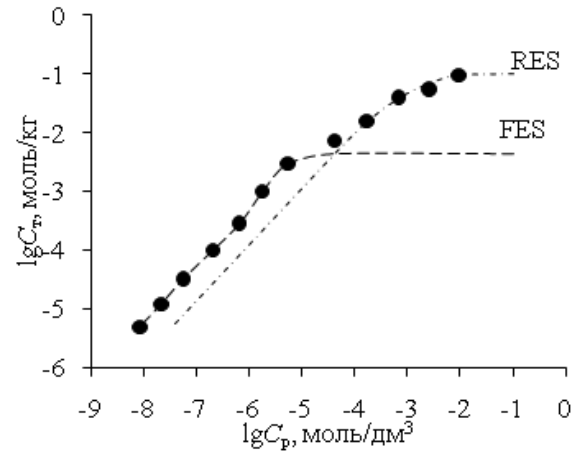

a

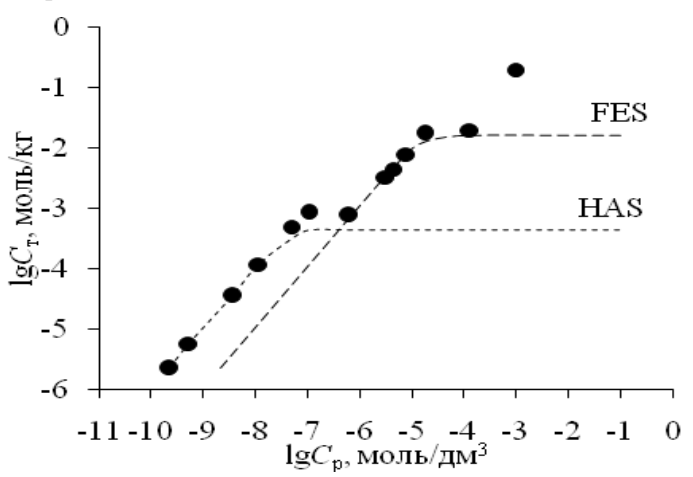

6

Рис. 2. Изотермы сорбции цезия образцами ГСШ (а) и АС (б) из раствора, $\mathrm{pH}=7.8 \pm 0.2$, ионная сила $\mathrm{I}=0.01 \mathrm{M} \mathrm{NaClO}_{4}$

Согласно номенклатуре ИЮПАК полученные изотермы сорбции относятся к I типу. Прямолинейные участки изотерм сорбции цезия обрабатывали с применением метода наименьших квадратов. Равновесные коэффициенты распределения цезия рассчитывали по параметрам уравнения линейной регрессии $\lg C_{\mathrm{r}}=\lg K_{d}+n \lg C_{\mathrm{p}}$. Установлено, что уравнения линейной регрессии в исходных концентрационных диапазонах цезия $5.6 \cdot 10^{-8}-4 \cdot 1 \cdot 10^{-5}$ моль/дм ${ }^{3}$ для образца ГСШ и $2.2 \cdot 10^{-8}-5 \cdot 10^{-6}, 3.5 \cdot 10^{-5}-2 \cdot 10^{-4}$ моль/дм ${ }^{3}$ для образца АС имеют следующий вид:

$$
\begin{aligned}
& \lg C_{\mathrm{T}}=2.63+0.99 \lg C_{\mathrm{p}} \\
& \lg C_{\mathrm{T}}=3.92+0.99 \lg C_{\mathrm{p}} \\
& \lg C_{\mathrm{T}}=2.91+0.98 \lg C_{\mathrm{p}}
\end{aligned}
$$

Рассчитанные из уравнений (5)-(7) коэффициенты распределения цезия для одного типа селективных сорбционных центров FES образца ГСШ, двух типов селективных сорбционных центров (HAS и FES) образца АC составляют $4.3 \cdot 10^{2}$, $8.3 \cdot 10^{3}$ и $8.1 \cdot 10^{2}$ дм $^{3} /$ кг соответственно, а величины сорбционной селективной емкости по цезию - 7.2, 0.4 и 14.6 ммоль/кг. Тангенс угла наклона прямолинейных участков изотермы сорбции цезия для данных концентрационных диапазонов практически равен единице, что свидетельствует о наличии обмена равновалентных ионов $\left(\mathrm{Cs}^{+}\right.$на $\mathrm{K}^{+}$). Установленный характер изотерм сорбции цезия для образцов ГСШ и АС согласуется с данными, полученным в работах $[17,23]$ при изучении сорбции катионов цезия на иллите. Сравнение экспериментальных данных показывает, что в результате кислотно-водной обработки исходного образца ГСШ величина селективной сорбционной емкости по цезию для образца алюмосиликатного сорбента увеличилась в 2.1 раза. Для количественного описания сорбции цезия из разбавленных растворов концентрацией менее $2 \cdot 10^{-4}$ моль/дм ${ }^{3}$ на образцах ГСШ и АС наиболее подходит модель Лэнгмюра, также возможно применение модели БЭТ для описания всей изотермы сорбции для образцов ГСШ и АС.

\section{Заключение}

В результате кислотно-водной обработки образца глинисто-солевого шлама, являющегося крупнотоннажным отходом калийного производства ОАО «Беларусь- 
калий» (Республика Беларусь), получен алюмосиликатный сорбент (АС). Показано, что данная обработка приводит к увеличению числа высокоселективных сорбционных центров в сорбенте в 1.3 раза за счет повышения содержания иллита. Установлены закономерности изменения коэффициентов распределения цезия на образце $\mathrm{AC}$ в области концентраций $\mathrm{Cs}^{+}$от $2.2 \cdot 10^{-8}$ до $3 \cdot 10^{-3}$ моль/дм ${ }^{3}$. Алюмосиликатный сорбент проявляет высокую селективность к $\mathrm{Cs}^{+}$при его концентрации в растворе менее $2 \cdot 10^{-4}$ моль/дм ${ }^{3}$. Перспективным направлением использования алюмосиликатного сорбента, полученного из глинисто-солевых шламов ОАО «Беларуськалий», может быть очистка природных вод от радионуклида ${ }^{137} \mathrm{Cs}$, а также реабилитация радиоактивно загрязненных территорий, направленная на снижение перехода ${ }^{137} \mathrm{Cs}$ из загрязненной радионуклидами почвы в сельскохозяйственные растения.

\section{Список литературы}

1. Милютин В.В., Некрасова Н.А., Харитонов О.В., Фирсова Л.А. и др. // Сорбичонные и хроматографические прочессы. 2016. Т. 16. № 3. С. 313-322.

2. Милютин В.В., Гелис В.М., Некрасова Н.А., Кононенко О.А. и др. // Радиохимия. 2012. T. 54. № 1. С. 71-74.

3. Тарасевич Ю.И. Природные сорбенты в процессах очистки воды. Киев. Наук. думка. $1981.206 \mathrm{c}$.

4. Рябчиков Б.Е. Очистка жидких радиоактивных отходов. М. ДеЛи принт. 2008. 516 с.

5. Мясоедова Г.В., Никашина В.А. // Рос. хим. ж. 2006. Т. 50. № 5. С. 55-63.

6. Милютин В.В., Везенцев А.И., Соколовский П.В., Некрасова Н.А. // Сорбиионные и хроматографические проиессы. 2014. Т. 14. № 5. C. 879-883.

7. Voronina A.V., Blinova M.O., Semenischev V.S., Gupta D.K. // J. Environ. Radioact. 2015. Vol. 144. pp. 103-112. DOI: 10.1016/j.jenvrad.2015.03.012.

8. Коноплева И.В. // Сорбичионные и хроматографические прочессы. 2016. Т. 16. № 4. C. 446-456.

9. Sawhney B.L. // Clay and Clay Miner. 1972. Vol. 20. pp. 93-100. DOI: 10.1346/CCMN.1972.0200208.

10. Осипов В.И., Соколов В.Н. Глины и их свойства. Состав, строение и формирование свойств. М. ГЕОС. 2013.576 с.

11. Прядко А.В., Жаркова В.О., Ершова Я.Ю., Тюпина Е.А. и др. // Успехи в химии и химической технологии. 2017. Т. 31. № 10. С. 19-21.

12. Москальчук Л.Н., Баклай А.А., Леонтьева Т.Г., Стреленко Д.К. // Труды БГТУ. 2015. № 3(167). С. 70-77.
13. Jeong, C.H., Kim, C.S., Kim, S.J., Park, S.W. // J. Environ. Sci. Health., Part A. 1996. Vol. 31(9). pp. 2173-2192. DOI: 10.1080/10934529609376485.

14. Санжарова Н.И., Сысоева А.А., Исамов Н.Н., Алексахин Р.М. и др. // Рос. хим. ж. 2005. T. 49. № 3. C. 26-34.

15. Соколова Т.А., Дронова Т.Я., Толпешта И.И. Глинистые минералы в почвах. Тула. Гриф и К. 2005. 336 с.

16. Ishidera T., Kurosawa S., Hayashi M., Uchikoshi K. et al. // Clay Miner. 2016. Vol. 51(2). pp. 161-172. DOI: 10.1180/claymin.2016.051.2.04.

17. Benedicto A., Missana T., Fernandez A.M. // Environ. Sci. Technol. 2014. Vol. 48. pp. 4909-4915. DOI: 10.1021/es5003346.

18. Durrant C.B., Begg J.D., Kersting A.B., Zavarin M. // Sci. Total Environ. 2018. Vol. 610-611. pp. 511-520. DOI: 10.1016/j.scitotenv.2017.08.122.

19. Королькова С.В. Автореф. канд. техн. наук. Белгород. 2012. 18 с.

20. Воронина А.В., Куляева И.О., Гупта Д.К. // Радиохимия. 2018. Т. 60. № 1. С. 3540.

21. Nakanishi T.B. // Proc. Jpn. Acad., Ser. B 94. 2018. Vol. 94(1). pp. 20-34. DOI: 10.2183/pjab.94.002.

22. Леонтьева Т.Г., Баклай А.А., Москальчук Л.Н. // Труды БГТУ. 2016. № 3. С. 74-80.

23. Cremers A., Elsen A., De Preter P, Maes A. // Nature. 1988. Vol. 335. No 6187. pp. 247249. DOI: $10.1038 / 335247 \mathrm{a} 0$.

24. Okumura M., Kerisit S., Bourg I.C., Lammers L.N. et al., // J. Environ. Radioact. 2018. Vol. 189. pp. 135-145. DOI: 10.1016/j.jenvrad.2018.03.011. 
25. Brouwer E., Baeyens B., Maes A., Cremers A. // J. Phus. Chem. 1983. Vol. 87. pp. 1213-1219.

26. Wauters J., Elsen A., Cremers A., Konoplev A.V. et al. // Applied Geochem. 1996. Vol. 11. pp. 589-594.

\section{References}

1. Miljutin V.V., Nekrasova N.A., Haritonov O.V., Firsova L.A. et al., Sorbtsionnye i khromatograficheskie protsessy, 2016, Vol. 16, No 3, pp. 313-322.

2. Mulyutin V.V., Gelis V.M., Nekrasova N.A., Kononenko O.A. et al., Radiochemistry, 2012, Vol. 54, No 1, pp. 75-78. DOI: 10.1134/S1066362212010110.

3. Tarasevich Yu.I. Prirodnye sorbenty v processah ochistki vody. Kiev, Nauk. Dumka, 1981, 206 p.

4. Rjabchikov B.E. Ochistka zhidkih radioaktivnyh othodov. Moscow, DeLi print, 2008, 516 p.

5. Mjasoedova G.V., Nikashina V.A., Ros. him. zh., 2006, Vol. 50, No 5, pp. 55-63.

6. Miljutin V.V., Vezencev A.I., Sokolovskij P.V., Nekrasova N.A., Sorbtsionnye i khromatograficheskie protsessy, 2014, Vol. 14(5), pp. 879-883.

7. Voronina A.V., Blinova M.O., Semenischev V.S., Gupta D.K., J. Environ. Radioact., 2015 , Vol. 144, pp. 103-112. DOI: 10.1016/j.jenvrad.2015.03.012.

8. Konopleva I.V., Sorbtsionnye $i$ khromatograficheskie protsessy, 2016, Vol. 16, No 4, pp. 446-456.

9. Sawhney B.L., Clay and Clay Miner., 1972, Vol. 20, pp. 93-100.

10. Osipov V.I., Sokolov V.N. Gliny i ih svojstva. Sostav, stroenie i formirovanie svojstv. M., GEOS, 2013, 576 p.

11. Prjadko A.V., Zharkova V.O., Ershova Ja.Ju., Tjupina E.A. et al., Uspehi v himii $i$ himicheskoj tehnologii, 2017, Vol. 31, No 10, pp. 19-21.

12. Moskal'chuk L.N., Baklaj A.A., Leont'eva T.G., Strelenko D.K., Trudy BGTU, 2015, No 3(167), pp. 70-77.

13. Jeong, C.H., Kim, C.S., Kim, S.J., Park, S.W., J. Environ. Sci. Health., Part A., 1996, Vol. 31(9), pp. 2173-2192. DOI: $10.1080 / 10934529609376485$.
27. ГОСТ 9169-75. Сырье глинистое для керамической промышленности. Классификация. М.: Изд-во стандартов. 1975. Введ. 01.06.1976. $8 \mathrm{c}$.

14. Sanzharova N.I., Sysoeva A.A., Isamov N.N., Aleksahin R.M., Kuznecov V.K., Zhigareva T.L., Ros. him. zh., 2005, Vol. 49, No 3, pp. 26-34.

15. Sokolova T.A., Dronova T.Ja., Tolpeshta I.I. Glinistye mineraly v pochvah. Tula, Grif i $\mathrm{K}, 2005,336 \mathrm{p}$.

16. Ishidera T., Kurosawa S., Hayashi M., Uchikoshi K., Beppu H., Clay Miner., 2016, Vol. 51(2), pp. 161-172. DOI:10.1180/claymin.2016.051.2.04.

17. Benedicto A., Missana T., Fernandez A.M., Environ. Sci. Technol., 2014, Vol. 48, pp. 4909-4915. DOI: 10.1021/es5003346.

18. Durrant C.B., Begg J.D., Kersting A.B., Zavarin M., Sci. Total Environ., 2018, Vol. 610611, pp. 511-520. DOI: 10.1016/j.scitotenv.2017.08.122.

19. Korol'kova S.V. Avtoref. kand. tehn. nauk. Belgorod, 2012, 18 p.

20. Voronina A.V., Kulyaeva I.O., Gupta D.K., Radiochemistry, 2018, Vol. 60, No 1, pp. 35-41. DOI: 10.1134/S106636221801006X.

21. Nakanishi T.B., Proc. Jpn. Acad., Ser. B 94, 2018, Vol. 94(1), pp. 20-34. DOI: 10.2183/pjab.94.002.

22. Leont'eva T.G., Baklaj A.A., Moskal'chuk L.N., Trudy BGTU, 2016, No. 3, pp. 74-80.

23. Cremers A., Elsen A., De Preter P, Maes A., Nature, 1988, Vol. 335, No 6187, pp. 247249. DOI: $10.1038 / 335247 \mathrm{a} 0$.

24. Okumura M., Kerisit S., Bourg I.C., Lammers L.N. et al., J. Environ. Radioact., 2018, Vol. 189, pp. 135-145. DOI: 10.1016/j.jenvrad.2018.03.011.

25. Brouwer E., Baeyens B., Maes A., Cremers A., J. Phus. Chem., 1983, Vol. 87, pp. 1213-1219.

26. Wauters J., Elsen A., Cremers A., Konoplev A.V. et al., Geochem., 1996, Vol. 11, pp. 589-594.

27. GOST 9169-75. Syr'e glinistoe dlja keramicheskoj promyshlennosti. Klassifikacija. M.: Izd-vo standartov, 1975, Vved. 01.06.1976, 8 p. 
Леонтьева Татьяна Геннадьевна - старший научный сотрудник лаборатории «Реабилитации загрязненных территорий». Государственное научное учреждение «Объединенный институт энергетических и ядерных исследований - Сосны» Национальной академии наук Беларуси, Минск, Республика Беларусь

Москальчук Леонид Николаевич - д. т. н., профессор кафедры физико-химических методов сертификации продукции Белорусского государственного технологического университета, Минск, Республика Беларусь

Баклай Анатолий Анатольевич - старший научный сотрудник лаборатории «Реабилитации загрязненных территорий». Государственное научное учреждение «Объединенный институт энергетических и ядерных исследований - Сосны» Национальной академии наук Беларуси, Минск, Республика Беларусь

Маковская Наталья Александровна к.б.н., заведующая лабораторией «Реабилитации загрязненных территорий». Государственное научное учреждение «Объединенный институт энергетических и ядерных исследований - Сосны» Национальной академии наук Беларуси, Минск, Республика Беларусь
Leont'yeva Tat'yana G. - Senior Researcher Remediation Techno Polluted Territories of the Laboratory. State Scientific Institution "Joint Institute for Power and Nuclear Research - Sosny" of the National Academy of Sciences of Belarus, Minsk, Republic of Belarus, e-mail: t.leontieva@tut.by

Moskal'chuk Leonid N. - Dr. of Technical Sciences, Professor of the Department of Physico-chemical methods of products certification, Belarusian State Technological University, Minsk, Republic of Belarus, E-mail: leonmosk@tut.by

Baklay Anatoliy A. - Senior Researcher Remediation Polluted Territories of the Laboratory. State Scientific Institution "Joint Institute for Power and Nuclear Research - Sosny" of the National Academy of Sciences of Belarus, Minsk, Republic of Belarus, E-mail: a.baklay@tut.by

Makovskaya Natal'ja A. - PhD (biology), Head of the Laboratory Remediation Polluted Territories. State Scientific Institution "Joint Institute for Power and Nuclear Research - Sosny" of the National Academy of Sciences of Belarus, Minsk, Republic of Belarus, E-mail: ferapontova@tut.by 